\title{
Effects of water and salt coordinated regulation at the different growth stages on water consumption and yield of tomato
}

\author{
Weihua Wang", Yidan Gong \\ (Faculty of Agriculture and Food, Kunming University of Science and Technology, Kunming 650500, China)
}

\begin{abstract}
The objective of this study was to explore the effects of different degrees of water and salt stress on the actual water consumption and soil salt accumulation of tomatoes and the salt tolerance characteristics of tomatoes under brackish water combined with regulated deficit irrigation mode. The greenhouse pot experiment was used to set three influencing factors, the irrigation water salinity S1 was $1.1 \mathrm{~g} / \mathrm{L}$ (local shallow groundwater), S2 was $2.0 \mathrm{~g} / \mathrm{L}$, and S3 was $4.0 \mathrm{~g} / \mathrm{L}$, respectively, and different degrees of water deficit (W1 ranged from 65\%-75\% Field Capacity (FC), W2 ranged from 55\%-65\% FC, W3 ranged from $45 \%-55 \% \mathrm{FC}$ ) and seedling stage (T1), blossoming and bearing fruits stage (T2) and mature picking stage (T3). The response of fresh fruit weight, stems and leaves weight, yield and water use efficiency of tomato under water and salt stress were monitored and analyzed. The results showed the coordinated regulation of water and salt can significantly reduce the electrical conductivity of the $0-30 \mathrm{~cm}$ soil of the tomato root system. The higher the salinity of irrigation water, the better the salt control effects of the coordinated regulation of water and salt; the coordinated regulation of water and salt at different growth stages had significant effects on the weight of fresh tomato fruits, the weight of stems and leaves and the yield. The salinity of irrigation water was in inverse proportion to the yield of tomatoes; In S1 treatment irrigation (irrigation water salinity was $1.1 \mathrm{~g} / \mathrm{L}$ ) under the mildly regulated deficit in the seedling stage (irrigation water was $55 \%-65 \%$ of the field water capacity) can effectively reduce the irrigation water volume during the whole growth stage while ensuring that there was no significant reduction in yield. The research results provided a scientific and reliable theoretical basis for the increase of local tomato production, the improvement of water use efficiency and the formulation of suitable irrigation patterns.
\end{abstract}

Keywords: tomato, coordinated regulation of water and salt, soil electrical conductivity, water consumption, yield DOI: $10.25165 /$ j.ijabe.20211404.6238

Citation: Wang W H, Gong Y D. Effects of water and salt coordinated regulation at the different growth stages on water consumption and yield of tomato. Int J Agric \& Biol Eng, 2021; 14(4): 96-105.

\section{Introduction}

Soil salinization is one of the serious environmental problems in the world, and it is also the main environmental factor restricting the growth and development of crops ${ }^{[1]}$, and with global climate change and the increasing proportion of farmland irrigation, it has a serious impact on agricultural production and development ${ }^{[2,3]}$. Therefore, the development and utilization of brackish water and saline water resources has a broad prospect. At present, the response of crops under water and salt stress, and the relationship among plants, water and soil in arid soil salinization environments have become key issues in the fields of agricultural water conservancy and environmental ecology ${ }^{[4]}$. According to the response of crops to water stress, most of the research conclusions are that water stress has a negative effect, causing damage to crop growth and development and reducing the yield, but at the same time, it will improve crop resistance and environmental adaptability $^{[5]}$. Research by Wang et al. ${ }^{[6]}$ showed that when lacking water, osmotic adjustment substances are accumulated in the cells of crops to reduce water potential and maintain normal life activities. Different salts and ion content in the soil have different effects on different growth stages of crops. Lower salt content has

\section{Received date: 2020-10-26 Accepted date: 2021-05-08}

Biographies: Yidan Gong, Master, research interest: water saving irrigation, Email: 1162774995@qq.com.

*Corresponding author: Weihua Wang, $\mathrm{PhD}$, Associate Professor, research interest: soil physics and water saving irrigation. Faculty of Agriculture and Food, Kunming University of Science and Technology, Kunming 650500, China. Tel: +86-13108855667, Email: wangweihua1220@163.com. no obvious effect on the physiological growth process of plants and crop yield. When the limit of the crop's characteristics is exceeded, stress will occur, so it is necessary to clarify the threshold that crops exceed a certain salt through researches. Research by Orsini et al. ${ }^{[7]}$ showed that a reasonable irrigation system can adjust the comprehensive effects brought by water, salt, and fertilizer, improve soil water holding capacity, and create a suitable micro-environment for crop growth and development. Study of Zhang et al. ${ }^{[8]}$ showed that applying moderate water stress during grape germination can increase grape yield, water production efficiency and irrigation water utilization rate; under the mild water stress treatment at the mature stage, grape quality indicators are significantly higher than the full irrigation treatment in the whole growth stage. Under the condition of lack of water resources, the water-saving system of regulated deficit irrigation should be popularized. Studying the fine management of the different growth stages of the same crop to adopting the most reasonable water resource allocation is an effective measure to improve the effect of water-saving irrigation and the benefits of economic crops.

At present, the researches on the application model of the impact of single regulated deficit irrigation or brackish water irrigation on crop yield and quality focus on the salinity of brackish water, the amount of freshwater irrigation, and the optimization of the allocation of freshwater in different growth stages ${ }^{[9]}$. However, it is still unclear how the change of soil solute potential affects the soil water condition, how the variation of soil water indirectly affects the temporal and spatial distribution of salt, and what effects the uneven distribution of soil water and salt will have on the 
parameters of the plant root system and canopy and yield. Combining brackish water irrigation with regulated deficit irrigation to formulate optimized irrigation models for different brackish water irrigation volumes in different growth stages, and to establish reasonable farmland water management systems under the coordinated control of water and salt, and finally achieve the production purposes which water-saving, increasing yield and enhancing quality have become the important topics.

Tomato fruit has rich nutrition and is planted widely. It is one of the main facility vegetables and economic crops in China. Tomatoes are extremely sensitive to water and have a long growth stage, there is a great difference in water requirements at different growth stages ${ }^{[10]}$. Combining with China's currently serious situation which is the shortage of agricultural water resources and the secondary salinization of the soil. This study proposed and evaluated the brackish water deficit-regulated precision irrigation model with the goal of water-saving and increasing production for tomatoes, the local economic crop. Using saline water with different salt concentrations and combining with a deficit-regulated irrigation model to study the impacts of coordinated regulation of water and salt in different growth stages on water use efficiency and yield, to determine suitable local water-saving and yield-increasing irrigation indicators, in order to make up for the lack of research on crop root growth mechanism under water and salt stress, to provide a reference for guiding the scientific production of tomatoes in this region, improving the level of water management, and formulating the best irrigation systems for crops.

\section{Materials and methods}

\subsection{General situations of the experimental area}

The experiment was carried out in a greenhouse for agricultural water and soil engineering in the College of Agriculture and Food, Kunming University of Science and Technology from June 2018 to November 2019, which was located in Chenggong District, Kunming City, Yunnan Province, China $\left(24^{\circ} 50^{\prime} 56^{\prime \prime} \mathrm{N}, 102^{\circ} 51^{\prime} 49^{\prime \prime} \mathrm{E}\right)$, The soil for the experiment was selected from the surface soil in the greenhouse. The soil texture was clay loam. The basic soil physical and chemical properties are in Table 1. The form of pot experiment was utilized. The flower pot for potting was a standard truncated cone, it was a plastic bucket with a top diameter of $28 \mathrm{~cm}$, a bottom diameter of $22 \mathrm{~cm}$, a height of $36 \mathrm{~cm}$ and a volume of $17756 \mathrm{~cm}^{3}$. The plastic bucket was perforated at the bottom in consideration of water permeability and air permeability of the roots, a bucket has 5 holes with a diameter of $5 \mathrm{~mm}$. The number and size of the hole of each bucket were the same. In order to accurately control irrigation and the distribution of soil salinity, try to put the soil through a $2 \mathrm{~mm}$ sieve after natural air drying, and fill the soil with a natural bulk density of $1.285 \mathrm{~g} / \mathrm{cm}^{3}$, the soil weight per pot was calculated to be $22.8 \mathrm{~kg}$. During the experiment period, the soil moisture content was measured by the weight method every other day. The irrigation scheme adopts drip irrigation, and the dripping flow rate was $1 \mathrm{~L} / \mathrm{h}$.

Table 1 Basic soil physical and chemical properties

\begin{tabular}{cccccc}
\hline Natural bulk density of soil & $\mathrm{pH}$ & Field capacity & Organic matter & $\begin{array}{c}\text { Alkaline hydrolysis } \\
\text { nitrogen }\end{array}$ & Available phosphorus \\
\hline $1.285 \mathrm{~g} / \mathrm{cm}^{3}$ & 6.7 & $22.56 \%$ & $10.11 \mathrm{~g} / \mathrm{kg}$ & $60.18 \mathrm{mg} / \mathrm{kg}$ & $30.05 \mathrm{mg} / \mathrm{kg}$ \\
\hline Available potassium & Soil depth & Clay & Silt & Sand & Soil texture \\
\hline $118.51 \mathrm{mg} / \mathrm{kg}$ & $0-30 \mathrm{~cm}$ & $17.08 \%$ & $29.65 \%$ & $53.27 \%$ & Clay loam \\
\hline
\end{tabular}

\subsection{Experimental design}

According to local planting mode, the test tomato 'Stone T1228' was purchased from Baoshan City, Yunnan Province. It is an unlimited growth type and is suitable for planting in a greenhouse in early spring or autumn. In this experiment, the growth stage of tomatoes was divided into three stages: seedling stage, blossoming and bearing fruits stage, and mature picking stage. Plump and disease-free tomato seeds were sown on a foam board with a well-divided grid (3 grains/grid) and contained nutrient medium (humus+perlite) for seeds germination. The floating board was placed in clear water for suspension breeding. When the seedlings grow to four leaves and one heart, the seedlings with the same growth were selected for transplantation and the seedlings were fixed after $7 \mathrm{~d}$ of transplantation. Tomato seedling stage (July): from field planting to the opening of the first flower of the first inflorescence. Flowering and fruit set period (August September): from the first flower of the first inflorescence to the first fruit of the first inflorescence to the size of a table tennis ball (diameter up to $3 \mathrm{~cm}$ ). Mature picking stage (September November): from the first fruit of the first inflorescence to the size of a ping-pong ball, to the end of fruit harvest until seedling pulling. The topping treatment was started at 5-6 ears/plant. According to the planting experiences of local farmers, 3 fruits were left in the first ear, 4 fruits in the second to fifth ears, and 5 fruits in the sixth ear. Fertilizer was applied 3 times during the whole growth stage of the tomatoes. The first time, the base fertilizer was applied before the tomato planting, the second time and the third time were applied when the fruits of the first and second ears swelled, application amount was $3.18 \mathrm{~g}$ urea $(\mathrm{N}), 1.81 \mathrm{~g}$ potassium sulfate $(\mathrm{K}), 4.62 \mathrm{~g}$ enzyme active phosphate fertilizer $(\mathrm{P})$ every time, the same amount of fertilizer for three times, using the local agronomic measures to control pests and weeds.

Three influencing factors were set up in the tomatoes brackish water regulated deficit irrigation experiment, namely the salinity of the irrigation water, different irrigation amount and the growth stages of the water deficit. Irrigation water salt concentration was set to 3 levels, namely low concentration salt stress S1, medium concentration salt stress S2 and high concentration salt stress $\mathrm{S}_{3}$, the irrigation water salinities were $1.1 \mathrm{~g} / \mathrm{L}, 2.0 \mathrm{~g} / \mathrm{L}$ and $4.0 \mathrm{~g} / \mathrm{L}$, respectively. The local shallow groundwater salinity was $1.1 \mathrm{~g} / \mathrm{L}$, and irrigation water with other salinities was configured by mixing $\mathrm{NaCl}$ with local shallow groundwater. Three kinds of water treatments were set up in this experiment, normal water treatment W1 (soil moisture content was $65 \%-75 \%$ Field Capacity (FC)), mild water stress treatment W2 (soil moisture content was 55\%-65\% FC), moderated water stress treatment W3 (soil moisture content was $45 \%$ to $55 \%$ FC). The period of water deficit occurred in the T1 (seedling stage), T2 (blossoming and bearing fruits stage), or T3 (mature picking stage). A control group was set up for each treatment with different salinity, and the control group was fully irrigated during the whole growth period, except for the three control groups (S1W1, S2W1, and S3W1), the other treatments were only irrigated with water deficit in one growth period and fully irrigated 
in the other two growth periods (Table 2). This experiment was a three-factor completely orthogonal experiment, so 18 treatments were set, and under the condition of three kinds of salt concentrations, a full irrigation treatment during the whole growth stage was set as a control treatment. Therefore, a total of 21 treatments were set up in this experiment, with seven repetitions for each treatment. Table 2 shows the description of the treatment settings for the irrigation test.

Table 2 Test treatment designs of tomato brackish water regulated deficit irrigation

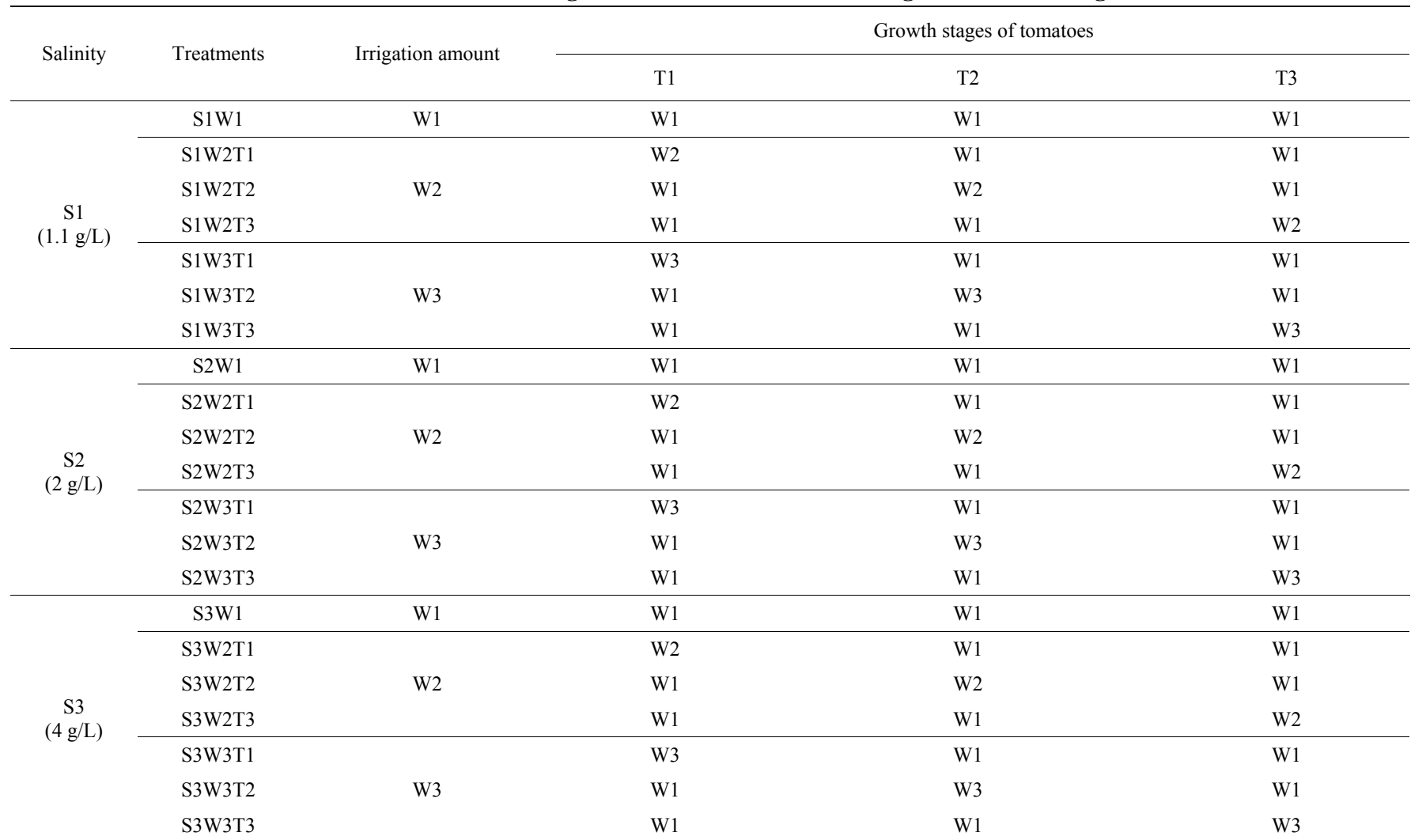

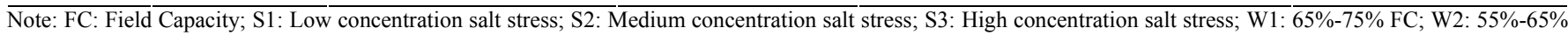
FC; W3: 45\%-55\% FC; T1: Seedling stage; T2: Blossoming and bearing fruits stage; T3: Mature picking stage, the same as below.

\subsection{Measurement items and methods}

2.3.1 Monitoring of meteorological data

1) Determination of temperature and humidity: The small meteorological instrument was used to observe the temperature and humidity in the greenhouse. Figure 1 shows the variation

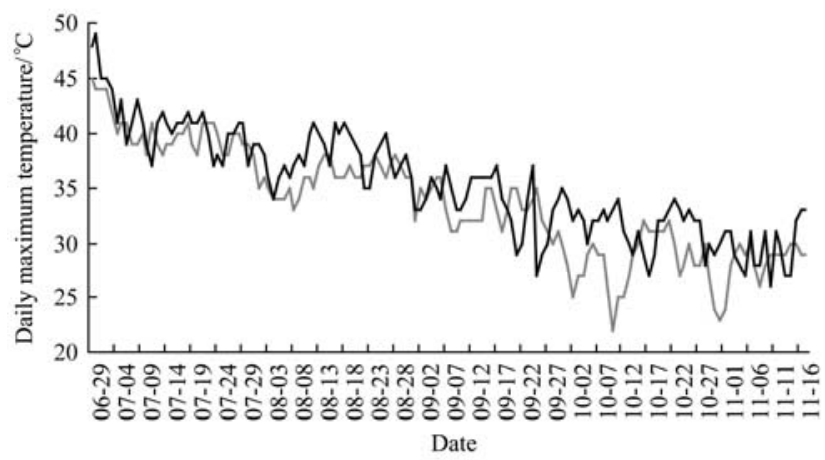

a. Daily maximum temperature curve of daily maximum temperature and daily mean humidity during the test stage in the greenhouse; 2) Determination of water surface evaporation: The E-601 evaporating dish was used for the measurement, and the observation time was 8:00 every morning.

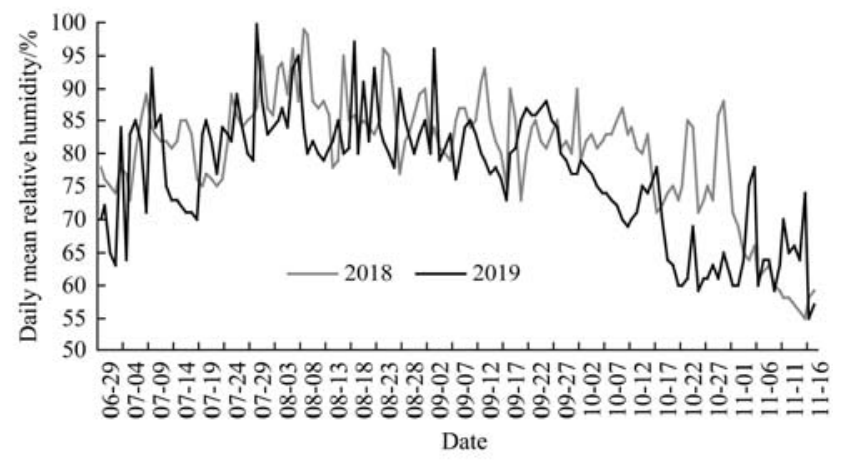

b. Daily mean relative humidity

Figure 1 Climate variables during the growing seasons of tomato in 2018 and 2019

\subsubsection{Determination of soil parameters}

1) Soil dry bulk density and field capacity: The indoor cutting ring method was adopted. The measuring depth was $30 \mathrm{~cm}$, measuring once every $10 \mathrm{~cm}$ and repeated 3 times each time; 2) Soil moisture content: It was calculated by weighing method; 3 ) Soil salinity: Collecting soil samples for each treatment every $10 \mathrm{~d}$ to detect soil salinity. The soil samples were collected in 3 layers at $10 \mathrm{~cm}$ intervals. Air-dried and ground passed through a $2 \mathrm{~mm}$ sieve and measured soil salinity in the laboratory at a soil-water ratio of 1:5. 4) Soil electrical conductivity (EC): EC measured about every $10 \mathrm{~d}$ during the entire growth stage. The soil was taken from the upper layer $(10 \mathrm{~cm})$, middle layer $(20 \mathrm{~cm})$, and bottom layer $(30 \mathrm{~cm})$, respectively, and finally calculated the change of the average soil electrical conductivity of $0-30 \mathrm{~cm}$. The determination of soil EC was divided into two parts, extraction and determination. The sample solution was extracted by the leaching method with a soil-water mass ratio of 1:5. The soil sample was air-dried soil, crushed with a mortar, passed through a $1 \mathrm{~mm}$ sieve, 
weighed into a centrifuge tube, added 5 times decarbonized distilled water, and shaken for $3 \mathrm{~min}$, centrifuge for $5 \mathrm{~min}$, used DDS-307A electrical conductivity meter to measure, repeated reading 3 times for each EC measurement. The above indicators were weighed every time after taking soil. After took the soil, added the soil according to the weighing number, marked the location of the drilling and taking soil, and took the soil diagonally, took soil for each potted plant at most twice.

2.3.3 Crop water consumption, water consumption intensity and water use efficiency

This study used the water balance method to calculate the actual water consumption of tomatoes with different irrigation treatments. The specific equation is

$$
\mathrm{ET}_{C}=P+I+\Delta W-R-D
$$

where, $\mathrm{ET}_{C}$ is crop water consumption, $\mathrm{mm}$; $P$ is precipitation, $\mathrm{mm}$; $I$ is irrigation water consumption, $\mathrm{mm} ; \Delta W$ is soil moisture change; $R$ is surface runoff, $\mathrm{mm} ; D$ is deep penetration, $\mathrm{mm}$. This experiment was a pot experiment conducted in a greenhouse. There was no precipitation and groundwater replenishment, and the irrigation had not deep leakage. Therefore, precipitation, surface runoff and deep leakage can be ignored, $P=0, R=0, D=0$. The equation can be simplified to Equation (2). According to the water balance equation, the water consumption equation for each growth stage of tomatoes can be simplified, such as

$$
\mathrm{ET}_{C}=I+\Delta W
$$

Water consumption intensity is the ratio of water consumption to the number of days of the growth stage in $\mathrm{mm} / \mathrm{d}$.

Water use efficiency $\left(\mathrm{kg} / \mathrm{m}^{3}\right)$ is the increase in output of the unit water consumption. The calculation equation of crop water use efficiency is

$$
\mathrm{WUE}=Y_{a} / \mathrm{ET}_{a}
$$

where, WUE is the crop water use efficiency, $\mathrm{kg} / \mathrm{m}^{3} ; Y_{a}$ is the crop economic yield, $\mathrm{t} / \mathrm{hm}^{2} ; \mathrm{ET}_{a}$ is the actual crop water consumption, $\mathrm{mm}$.

\subsubsection{Determination of tomato yield}

Chose three tomato plants with the same growth vigor for each treatment, measured the fruit diameter with a vernier caliper when the tomatoes were mature for picking.

In the late experiment stage, the fruits were fully mature, three tomato plants with similar growth vigor were selected in each treatment, and all the fruits were picked and washed with distilled water and dried, then weighed on an electronic scale to record the fresh weight of the fruits and calculate the average value.

According to the yield per plant and the planting experiences of the local farmers, it was calculated by planting 27000 plants $/ \mathrm{hm}^{2}$.

\subsection{Data processing and analysis}

Test data and graphs were processed by Excel, SPSS 19.0 (Analysis of variance and significance, the significant difference was 0.05) and Origin 2018.

\section{Results}

\subsection{Changeable rule of soil electrical conductivity}

Table 3 shows the change of the average electrical conductivity of the soil from 0 to $30 \mathrm{~cm}$ in each growth stage from 2018 to 2019 . In 2018, the variation range of average electrical conductivity of the soil during the seedling stage, blossoming and bearing fruits stage, and fruiting stage are 144.270-1002.211 $\mu \mathrm{m} / \mathrm{cm}, 179.652-$ $1145.670 \mu \mathrm{m} / \mathrm{cm}$, and $219.949-1232.287 \mu \mathrm{m} / \mathrm{cm}$, respectively. Under each treatment, the soil electrical conductivity accumulates continuously with the growth of crops. Similar to 2018, the variation range of soil electrical conductivity in each stage in 2019 were 130.887-991.612 $\mu \mathrm{m} / \mathrm{cm}, 166.561-1129.011 \mu \mathrm{m} / \mathrm{cm}, 213.935$ $1232.287 \mu \mathrm{m} / \mathrm{cm}$. Due to the two-year difference in temperature, the amount of irrigation water (crop water consumption) in 2019 was more than in 2018 , so the accumulated salt in the soil was higher than in 2018, the average increase of each treatment was $2.34 \%$. So, the soil electrical conductivity under brackish water irrigation increases with the increase of irrigation quantity. The reasons for the increase were related to the temperature and humidity in the greenhouse. According to Figure 1, the daily maximum temperature in 2019 was higher than that in 2018 for most of the time. High temperature and low humidity accelerated the evaporation and transpiration of plants, and increase the intensity of water consumption.

Taking the average soil electrical conductivity of the mature picking stage in 2019 as an example, analyzed the change law of soil electrical conductivity of each treatment under different water-salt regulations. In the freshwater irrigation treatments in 2019, compared with S1W1 in the seedling stage, conductivities of S1W2T1 and S1W3T1 treatments were lower than that of other treatments, with a decrease of $8.5 \%$ and $9.1 \%$, respectively, compared with $\mathrm{S} 1 \mathrm{~W} 1$ in the blossoming and bearing fruits stage, the soil electrical conductivity of S1W2T2 and S1W3T2 treatments were lower than that of other treatments, with a decrease of $9.3 \%$ and $9.7 \%$, respectively, compared with S1W1 in the mature picking stage, the soil electrical conductivity of S1W2T3 and S1W3T3 treatments were lower than other treatments, with a decrease of $5.4 \%$ and $5.1 \%$, respectively. Therefore, water deficit during the blossoming and bearing fruits stage and the seedling stage can significantly reduce the salt accumulation in the soil, and it also indicates that the blossoming and bearing fruits stage and the seedling stage under freshwater conditions are the key stages for water consumption.

Taking the change of the average electrical conductivity of the $0-30 \mathrm{~cm}$ soil of the root system during the fruiting stage in 2019 as an example, when the irrigation water salinity was $2 \mathrm{~g} / \mathrm{L}$, compared with fully irrigation $\mathrm{S} 2 \mathrm{~W} 1$, the soil electrical conductivity of S2W2T1, S2W2T2, S2W3T1, S2W3T2 treatments in the seedling stage, blossoming and bearing fruits stage, and mature picking stage are reduced significantly, and the reduction rate was smaller than the treatment of fresh water irrigation, with a reduction of $2.3 \%, 4.8 \%, 3.9 \%$ and $7.1 \%$, respectively. However, the soil electrical conductivity of S2W2T3 and S2W3T3 in the fruiting stage of the deficit treatment has little difference, which was $0.8 \%$ and $0.7 \%$ lower than that of S2W1, respectively. This shows that the irrigation in the blossoming and bearing fruits stage and fruiting stage are also affected by salt stress after the seedling stage was irrigated with brackish water, but the self-consumption of water in the fruiting stage was less than that in the blossoming and bearing fruits stage, so the impact on the fruiting stage was less.

With the increase of the salt concentration in the soil, the soil conductivity under the full irrigation treatments (S1W1, S2W1 and S3W1) in 2018 and 2019 were significantly higher than other treatments. When the salinity was $4 \mathrm{~g} / \mathrm{L}$, the soil electrical conductivity of the fruiting stage under the full irrigation treatment in 2018 and 2019 increased by $4.8 \%$ and $5.3 \%$ on average compared with other treatments. This indicates that when the salinity of irrigation reaches a certain level, water deficit in any growth stage will significantly reduce the accumulation of salt in the soil. Therefore, when the salinity reaches $4 \mathrm{~g} / \mathrm{L}$, proper water control at different growth stages will significantly improve soil salinization. 
Table 3 Soil EC at 0-30 cm with different growth stages

\begin{tabular}{|c|c|c|c|c|c|c|}
\hline \multirow{2}{*}{ Treatments } & \multicolumn{2}{|c|}{ Electric conductivity of $\mathrm{T} 1 / \mu \mathrm{s} \cdot \mathrm{cm}^{-1}$} & \multicolumn{2}{|c|}{ Electric conductivity of $\mathrm{T} 2 / \mu \mathrm{s} \cdot \mathrm{cm}^{-1}$} & \multicolumn{2}{|c|}{ Electric conductivity of $\mathrm{T} 3 / \mu \mathrm{s} \cdot \mathrm{cm}^{-1}$} \\
\hline & 2018 & 2019 & 2018 & 2019 & 2018 & 2019 \\
\hline S1W1 & $154.135 \pm 11.75$ & $139.672 \pm 9.24$ & $200.341 \pm 14.78$ & $187.882 \pm 15.24$ & $247.581 \pm 16.14$ & $229.791 \pm 20.71$ \\
\hline S1W2T1 & $143.211 \pm 16.10$ & $127.770 \pm 7.87$ & $200.312 \pm 13.92$ & $187.271 \pm 20.13$ & $249.681 \pm 20.81$ & $231.400 \pm 17.74$ \\
\hline $\mathrm{S} 1 \mathrm{~W} 2 \mathrm{~T} 2$ & $154.135 \pm 13.25$ & $139.762 \pm 11.51$ & $181.652 \pm 16.01$ & $168.561 \pm 13.21$ & $219.949 \pm 17.74$ & $204.284 \pm 17.71$ \\
\hline S1W2T3 & $154.134 \pm 10.41$ & $139.672 \pm 8.91$ & $200.340 \pm 15.21$ & $187.713 \pm 17.42$ & $242.139 \pm 21.25$ & $217.382 \pm 20.13$ \\
\hline S1W3T2 & $154.135 \pm 18.11$ & $139.671 \pm 11.21$ & $181.769 \pm 13.87$ & $169.599 \pm 14.21$ & $230.228 \pm 18.16$ & $213.935 \pm 18.54$ \\
\hline S1W3T3 & $154.135 \pm 13.65$ & $139.672 \pm 14.07$ & $200.341 \pm 17.15$ & $187.881 \pm 15.32$ & $243.602 \pm 15.73$ & $218.072 \pm 17.77$ \\
\hline $\mathrm{S} 2 \mathrm{~W} 1$ & $447.707 \pm 27.21$ & $434.197 \pm 31.23$ & $524.551 \pm 25.87$ & $510.334 \pm 25.53$ & $667.782 \pm 27.87$ & $655.131 \pm 30.57$ \\
\hline $\mathrm{S} 2 \mathrm{~W} 2 \mathrm{~T} 1$ & $385.476 \pm 21.32$ & $373.409 \pm 20.45$ & $520.692 \pm 30.76$ & $507.231 \pm 30.21$ & $651.818 \pm 28.81$ & $640.063 \pm 32.76$ \\
\hline $\mathrm{S} 2 \mathrm{~W} 2 \mathrm{~T} 2$ & $447.707 \pm 35.21$ & $434.197 \pm 18.76$ & $498.710 \pm 33.61$ & $485.997 \pm 31.27$ & $605.008 \pm 26.68$ & $623.685 \pm 34.21$ \\
\hline $\mathrm{S} 2 \mathrm{~W} 2 \mathrm{~T} 3$ & $447.707 \pm 29.57$ & $434.197 \pm 25.49$ & $524.551 \pm 36.57$ & $510.333 \pm 32.21$ & $662.912 \pm 30.12$ & $649.890 \pm 33.76$ \\
\hline S2W3T2 & $447.707 \pm 26.43$ & $434.197 \pm 32.01$ & $499.014 \pm 35.51$ & $486.110 \pm 30.13$ & $620.972 \pm 29.87$ & $608.617 \pm 34.89$ \\
\hline S2W3T3 & $447.706 \pm 31.24$ & $434.197 \pm 35.51$ & $524.551 \pm 39.21$ & $510.334 \pm 33.41$ & $656.688 \pm 34.51$ & $650.545 \pm 31.68$ \\
\hline S3W1 & $1002.211 \pm 49.97$ & $991.612 \pm 49.21$ & $1145.670 \pm 59.79$ & $1129.011 \pm 40.31$ & $1247.298 \pm 42.87$ & $1232.287 \pm 49.98$ \\
\hline S3W2T1 & $863.906 \pm 41.22$ & $855.781 \pm 50.17$ & $1121.110 \pm 61.23$ & $1101.239 \pm 43.21$ & $1193.770 \pm 47.92$ & $1186.692 \pm 51.27$ \\
\hline $\mathrm{S} 3 \mathrm{~W} 2 \mathrm{~T} 2$ & $1002.211 \pm 50.24$ & $991.612 \pm 54.67$ & $1058.801 \pm 58.71$ & $1049.886 \pm 45.67$ & $1144.450 \pm 50.67$ & $1137.401 \pm 53.98$ \\
\hline $\mathrm{S} 3 \mathrm{~W} 2 \mathrm{~T} 3$ & $1002.210 \pm 55.21$ & $991.613 \pm 57.24$ & $1145.670 \pm 61.51$ & $1129.012 \pm 51.78$ & $1224.482 \pm 54.76$ & $1213.803 \pm 58.17$ \\
\hline S3W3T1 & $858.896 \pm 42.01$ & $847.828 \pm 43.66$ & $1113.378 \pm 51.27$ & $1100.309 \pm 55.87$ & $1188.074 \pm 48.67$ & $1176.834 \pm 50.32$ \\
\hline S3W3T2 & $1002.211 \pm 48.16$ & $991.612 \pm 59.91$ & $1091.093 \pm 58.91$ & $1054.876 \pm 52.71$ & $1123.261 \pm 55.87$ & $1120.149 \pm 53.98$ \\
\hline S3W3T3 & $1002.211 \pm 53.88$ & $991.612 \pm 55.39$ & $1145.670 \pm 61.33$ & $1129.011 \pm 59.98$ & $1214.750 \pm 60.61$ & $1205.177 \pm 55.17$ \\
\hline
\end{tabular}

\subsection{Water consumption and water consumption rate}

Figure 2 shows that no matter which growth stages occur the water deficit in different degrees, there was a significant downward trend with the increasing of irrigation salinity gradient during the whole growth stages. In 2018 and 2019, the total water consumption of tomatoes during the whole growth stage was 357.51-244.79 mm and 393.91-266.91 mm, respectively. Among them, the water consumption was the largest under the low-salt full irrigation treatment, the water consumption of the salinity was $4 \mathrm{~g} / \mathrm{L}$ and the severe deficit treatment during the mature picking stage was the smallest. With the increase of salt concentration in the soil, the water consumption of each treatment under full irrigation was significantly reduced during the full growth stage. In 2018, compared with the low-salt full irrigation treatment, the water consumption of the full irrigation treatments with a salinity of $2 \mathrm{~g} / \mathrm{L}$ and $4 \mathrm{~g} / \mathrm{L}$ reduced by $5.3 \%$ and $8.8 \%$, respectively. It can be seen

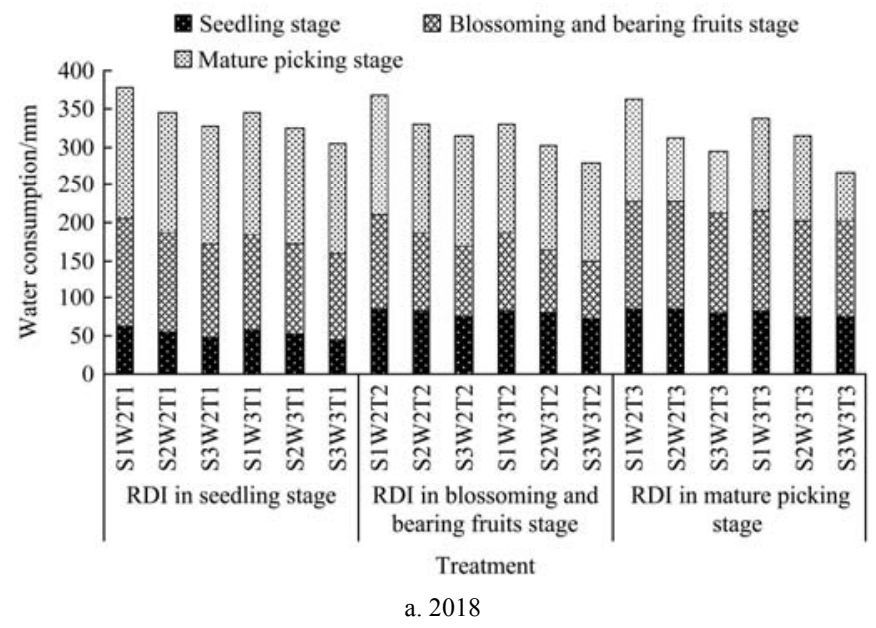

that salt stress can significantly reduce crop water consumption. When considering the total crop water consumption under the coordinated regulation of different levels of water and salt, it can be found that under the condition of water deficit during the blossoming and bearing fruits stage in 2018 and 2019, the relationships between the total irrigation amount during the whole growth stage are S1W3T2 less than S2W2T1, S2W3T2 greater than S3W2T2, and the seedling stage was consistent with the mature picking stage, its total irrigation amount relationships are S1W3T1 greater than S2W2T1, S2W3T1 greater than S3W2T1, S1W3T3 greater than S2W2T3, S2W3T3 greater than S3W2T3, indicating that the blossoming and bearing fruits stage was a sensitive stage for crop water consumption under the freshwater regulated deficit irrigation. Under the coordinated regulation of water and salt, irrigation salinity plays a major role in reducing crop water consumption, and the impact degree was greater than water deficit.

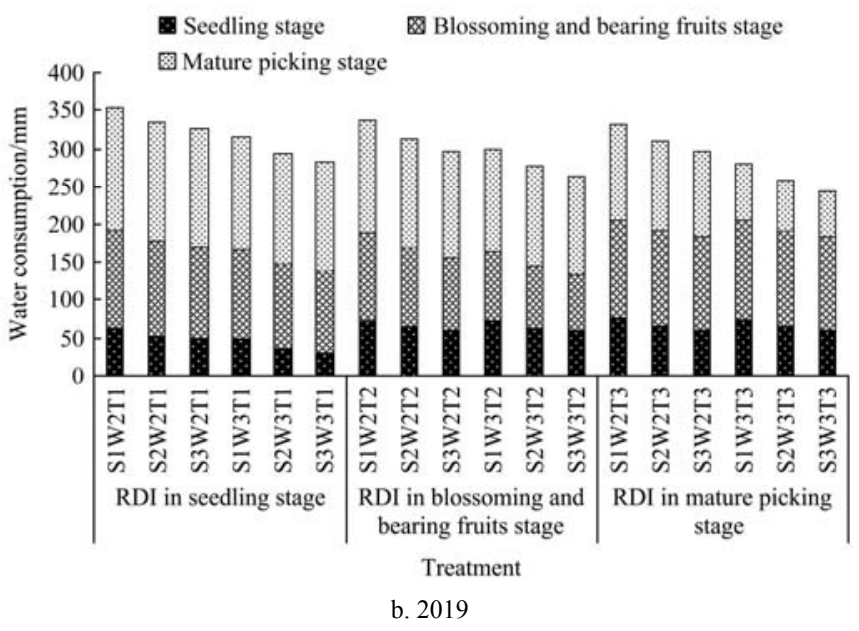

Note: RDI: Regulated deficit irrigation. S1: Low concentration salt stress; S2: Medium concentration salt stress; S3: High concentration salt stress. W1: $65 \%-75 \% \mathrm{FC}$; W2: 55\%-65\%FC; W3: 45\%-55\% FC; T1: Seedling stage; T2: Blossoming and bearing fruits stage; T3: Mature picking stage, the same as below.

Figure 2 Effects of coordinated regulation of water and salt at different growth stages on water consumption during the whole growth stage in 2018 and 2019 
Under the low-salt irrigation treatment, compared with full irrigation during the whole growth stage, there was no significant difference in water consumption in 2018 and 2019 under S1W1 and S1W2T1 treatments when slightly regulated deficit irrigation during the seedling stage. However, comparing with S1W1, the water consumption of crops under the S1W2T1 treatment during the mature picking stage in 2018 and 2019 increased by $5.4 \%$ and $4.4 \%$ respectively. This shows that only mild water stress in the seedling stage has little effect on water consumption for the subsequent growth stage of tomatoes, and instead, it promotes the water consumption in the later stage and increases the water consumption intensity of the crop. Under the mild water deficit treatment with irrigation water salinity of $2 \mathrm{~g} / \mathrm{L}$, the same laws are shown. When there was a slight water deficit in the seedling stage, compared with full irrigation during the whole growth stage, the water consumption during blossoming and bearing fruits stage under the S2W2T1 intersecting S2W1 treatment increased by $0.29 \%$ and $0.42 \%$, respectively, in 2018 and 2019 , and the water consumption in the fruiting stage increased by $2.65 \%$ and $5.26 \%$, respectively. However, when the salinity increased to $4 \mathrm{~g} / \mathrm{L}$, this rule disappeared. Compared with the S3W1 treatment, the water consumption of tomatoes during the blossoming and bearing fruits stage and the mature picking stage was reduced after the mild water deficit treatment at the seedling stage, in 2018 and 2019. This shows that, when the tomato was irrigated with fresh water, light water deficit irrigation at the seedling stage had no effect on the water consumption of the tomato in the later stage, and can even increase the water consumption intensity of the tomato during the blossoming and bearing fruits stage and the mature picking stage.

Table 4 Influences of water and salt stress on the water consumption rate of tomato in different growth stages in2018 and 2019

\begin{tabular}{|c|c|c|c|c|c|c|}
\hline \multirow{2}{*}{ Treatment } & \multicolumn{2}{|c|}{ Water consumption rate of $\mathrm{T} 1 / \mathrm{mm} \cdot \mathrm{d}^{-1}$} & \multicolumn{2}{|c|}{ Water consumption rate of $\mathrm{T} 2 / \mathrm{mm} \cdot \mathrm{d}^{-1}$} & \multicolumn{2}{|c|}{ Water consumption rate of $\mathrm{T} 3 / \mathrm{mm} \cdot \mathrm{d}^{-1}$} \\
\hline & 2018 & 2019 & 2018 & 2019 & 2018 & 2019 \\
\hline S1W1 & $2.30 \pm 0.19^{\mathrm{a}}$ & $2.65 \pm 0.17^{\mathrm{a}}$ & $2.91 \pm 0.03^{\mathrm{a}}$ & $3.19 \pm 0.21^{\mathrm{a}}$ & $2.35 \pm 0.07^{b}$ & $2.55 \pm 0.08^{\mathrm{b}}$ \\
\hline S1W2T1 & $1.96 \pm 0.02^{\mathrm{d}}$ & $1.97 \pm 0.05^{\mathrm{e}}$ & $2.89 \pm 0.01^{\mathrm{bc}}$ & $3.14 \pm 0.13^{\mathrm{a}}$ & $2.48 \pm 0.05^{\mathrm{a}}$ & $2.66 \pm 0.06^{\mathrm{a}}$ \\
\hline S1W2T2 & $2.32 \pm 0.37^{\mathrm{a}}$ & $2.67 \pm 0.13^{\mathrm{a}}$ & $2.55 \pm 0.02^{\mathrm{e}}$ & $2.78 \pm 0.22^{\mathrm{e}}$ & $2.27 \pm 0.06^{\mathrm{c}}$ & $2.43 \pm 0.05^{\mathrm{c}}$ \\
\hline S1W2T3 & $2.35 \pm 0.03^{\mathrm{a}}$ & $2.69 \pm 0.20^{\mathrm{a}}$ & $2.92 \pm 0.01^{\mathrm{ab}}$ & $3.16 \pm 0.30^{\mathrm{a}}$ & $1.91 \pm 0.02^{\mathrm{f}}$ & $2.08 \pm 0.06^{\mathrm{g}}$ \\
\hline S1W3T2 & $2.29 \pm 0.38^{\mathrm{ab}}$ & $2.63 \pm 0.11^{\mathrm{a}}$ & $2.01 \pm 0.02^{\mathrm{h}}$ & $2.27 \pm 0.18^{\mathrm{i}}$ & $2.06 \pm 0.02^{\mathrm{e}}$ & $2.21 \pm 0.04^{\mathrm{e}}$ \\
\hline S1W3T3 & $2.33 \pm 0.31^{\mathrm{a}}$ & $2.69 \pm 0.24^{\mathrm{a}}$ & $2.93 \pm 0.03^{\mathrm{ab}}$ & $3.18 \pm 0.32^{\mathrm{a}}$ & $1.52 \pm 0.01^{\mathrm{h}}$ & $1.29 \pm 0.04^{\mathrm{k}}$ \\
\hline $\mathrm{S} 2 \mathrm{~W} 1$ & $1.97 \pm 0.12^{\mathrm{d}}$ & $2.47 \pm 0.15^{\mathrm{bc}}$ & $2.79 \pm 0.17^{\mathrm{c}}$ & $2.93 \pm 0.30^{\mathrm{b}}$ & $2.31 \pm 0.13^{\mathrm{b}}$ & $2.41 \pm 0.05^{\mathrm{c}}$ \\
\hline $\mathrm{S} 2 \mathrm{~W} 2 \mathrm{~T} 1$ & $1.31 \pm 0.08^{\mathrm{g}}$ & $1.75 \pm 0.09^{\mathrm{f}}$ & $2.80 \pm 0.21^{\mathrm{bc}}$ & $2.94 \pm 0.26^{\mathrm{b}}$ & $2.37 \pm 0.05^{\mathrm{b}}$ & $2.55 \pm 0.06^{\mathrm{b}}$ \\
\hline $\mathrm{S} 2 \mathrm{~W} 2 \mathrm{~T} 2$ & $2.02 \pm 0.16^{\mathrm{cd}}$ & $2.50 \pm 0.23^{\mathrm{b}}$ & $2.34 \pm 0.15^{\mathrm{g}}$ & $2.37 \pm 0.21^{\mathrm{h}}$ & $2.21 \pm 0.12^{\mathrm{c}}$ & $2.32 \pm 0.04^{\mathrm{d}}$ \\
\hline $\mathrm{S} 2 \mathrm{~W} 2 \mathrm{~T} 3$ & $2.03 \pm 0.21^{\mathrm{cd}}$ & $2.54 \pm 0.07^{\mathrm{b}}$ & $2.82 \pm 0.24$ & $2.94 \pm 0.28^{\mathrm{b}}$ & $1.70 \pm 0.05^{\mathrm{g}}$ & $1.85 \pm 0.03^{\mathrm{i}}$ \\
\hline $\mathrm{S} 2 \mathrm{~W} 3 \mathrm{~T} 2$ & $1.99 \pm 0.08^{\mathrm{d}}$ & $2.50 \pm 0.13^{\mathrm{b}}$ & $1.87 \pm 0.09^{\mathrm{i}}$ & $2.11 \pm 0.07^{\mathrm{j}}$ & $2.02 \pm 0.08^{\mathrm{e}}$ & $2.11 \pm 0.07^{\mathrm{f}}$ \\
\hline S2W3T3 & $2.00 \pm 0.11^{\mathrm{cd}}$ & $2.57 \pm 0.32^{\mathrm{b}}$ & $2.82 \pm 0.14$ & $2.95 \pm 0.26^{\mathrm{b}}$ & $1.39 \pm 0.04^{\mathrm{i}}$ & $1.12 \pm 0.02^{1}$ \\
\hline S3W1 & $1.78 \pm 0.12^{\mathrm{f}}$ & $2.32 \pm 0.21^{\mathrm{c}}$ & $2.69 \pm 0.15^{\mathrm{d}}$ & $2.80 \pm 0.22^{\mathrm{c}}$ & $2.28 \pm 0.06^{\mathrm{c}}$ & $2.32 \pm 0.05^{\mathrm{d}}$ \\
\hline S3W2T1 & $1.24 \pm 0.09^{\mathrm{h}}$ & $1.48 \pm 0.07^{\mathrm{h}}$ & $2.50 \pm 0.22^{\mathrm{e}}$ & $2.56 \pm 0.26^{\mathrm{d}}$ & $2.34 \pm 0.11^{\mathrm{b}}$ & $2.46 \pm 0.05^{\mathrm{c}}$ \\
\hline $\mathrm{S} 3 \mathrm{~W} 2 \mathrm{~T} 2$ & $1.81 \pm 0.13 \mathrm{e}$ & $2.34 \pm 0.12^{\mathrm{c}}$ & $1.82 \pm 0.21^{\mathrm{i}}$ & $2.01 \pm 0.18^{\mathrm{j}}$ & $2.17 \pm 0.07^{\mathrm{d}}$ & $2.23 \pm 0.03^{\mathrm{e}}$ \\
\hline S3W2T3 & $1.76 \pm 0.07^{\mathrm{f}}$ & $2.34 \pm 0.08^{\mathrm{c}}$ & $2.72 \pm 0.18^{\mathrm{c}}$ & $2.83 \pm 0.20^{\mathrm{c}}$ & $1.51 \pm 0.05^{\mathrm{h}}$ & $1.74 \pm 0.04^{\mathrm{j}}$ \\
\hline S3W3T1 & $0.94 \pm 0.03^{j}$ & $1.42 \pm 0.09^{\mathrm{i}}$ & $2.43 \pm 0.16^{\mathrm{ef}}$ & $2.53 \pm 0.31^{\mathrm{g}}$ & $2.18 \pm 0.06^{\mathrm{d}}$ & $2.25 \pm 0.07^{\mathrm{e}}$ \\
\hline S3W3T2 & $1.87 \pm 0.16^{\mathrm{e}}$ & $2.32 \pm 0.32^{\mathrm{c}}$ & $1.65 \pm 0.08^{j}$ & $1.65 \pm 0.18^{\mathrm{k}}$ & $1.97 \pm 0.04^{\mathrm{f}}$ & $2.03 \pm 0.08^{\mathrm{h}}$ \\
\hline S3W3T3 & $1.88 \pm 0.20^{\mathrm{e}}$ & $2.37 \pm 0.26^{\mathrm{c}}$ & $2.72 \pm 0.21^{\mathrm{c}}$ & $2.80 \pm 0.23^{\mathrm{c}}$ & $0.96 \pm 0.01^{\mathrm{i}}$ & $1.00 \pm 0.01^{\mathrm{m}}$ \\
\hline
\end{tabular}

Note: Different lowercase letters in the same column represent significant differences among treatments, with a confidence interval of $p<0.05$.

\subsection{Yield and water use efficiency}

\subsubsection{Effect of water and salt regulation on tomato fruit diameter}

Fruit diameter is the most intuitive index of fruit yield and quality. The change laws of fruit diameter in 2018 and 2019 were similar. This study took the change of fruit diameter in 2018 as an example. As shown in Figure 3, the fruit diameter of the mildly regulated deficit W2T1 treatment under fresh water irrigation (S1) in 2018 and 2019 was the largest, and the horizontal and vertical diameters of tomato fruits were similar. Under mild water deficit treatment, the seedling stage, blossoming and bearing fruits stage, and fruiting stage were increased by $0.23 \%$, decreased by $1.03 \%$, and decreased by $0.34 \%$ compared with the control group W1S1, and under the moderate water deficit W2 treatment, these decreased by $1.72 \% 3.33 \%, 2.41 \%$ respectively compared with the control group. It can be seen that, under low salt stress, with the increase of water deficit degree, the fruit diameter decrease continuously. The results obtained from S2 and S3 salt treatment were significantly different from S1 treatment. Under moderate salt stress, the fruit diameter reduced an average of $3.01 \%$ than the lower salt stress S1 treatment, and the high salt stress S3 treatment reduced an average of $18.27 \%$ than $\mathrm{S} 1$ treatment. The horizontal and vertical diameters of the fruits with W3T2 treatment under S3 salt stress were the smallest, W3T2 treatment decreased by $2.39 \%$ on average than W3T1 treatments under S1 and S2 salinity, while under severe salt stress S3 treatments, W3T2 treatments decreased by $1.35 \%$ than $\mathrm{W} 3 \mathrm{~T} 1$ treatments. While in the $\mathrm{S} 1$ and $\mathrm{S} 2$ salt concentrations, S1W3T1 and S2W3T1 treatments were reduced by an average of $1.72 \%$ than the control S1W1 and S2W1 treatments. In the severe salt stress $\mathrm{S} 3, \mathrm{~S} 3 \mathrm{~W} 3 \mathrm{~T} 1$ was reduced by $11.44 \%$ than the control S3W1. It can be seen that under severe salt stress (S3, salinity was $4 \mathrm{~g} / \mathrm{L}$ ), compared with low-salt S1 and medium-salt S2 treatments under moderate water deficit irrigation, W3 irrigation with moderate water deficit at T2 during blossoming and bearing fruits stage was reduced small amplitude, but the moderate water deficit treatment S3W3T1 at the seedling stage under severe salt stress reduced significantly than the control group S3W1. This was because the moderate water-salt stress exceeds the self-regulating range of tomatoes in the seedling stage, which 
seriously affects the development of the blossoming and bearing fruits stage and fruiting stage. The above summarized that when the irrigation water salinity was the same, the slight water deficit at the seedling stage and fruiting stage has little effect on the tomato fruit diameter. Under mild salt stress (S1), the slight water deficit at the seedling stage can even promote fruit development. The effect of water deficit on fruit diameter during the growth stage was: blossoming and bearing fruits stage greater than mature picking stage greater than the seedling stage.

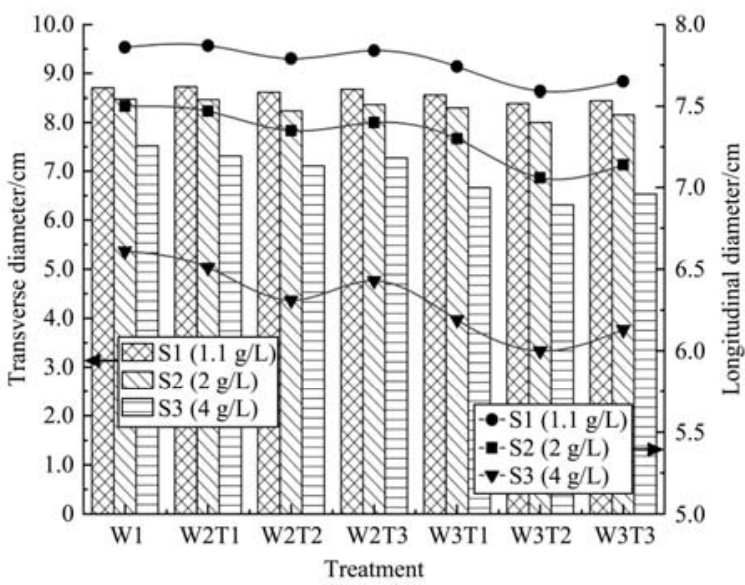

Figure 3 Effects of different water and salt control treatments on tomato fruit diameter in 2018

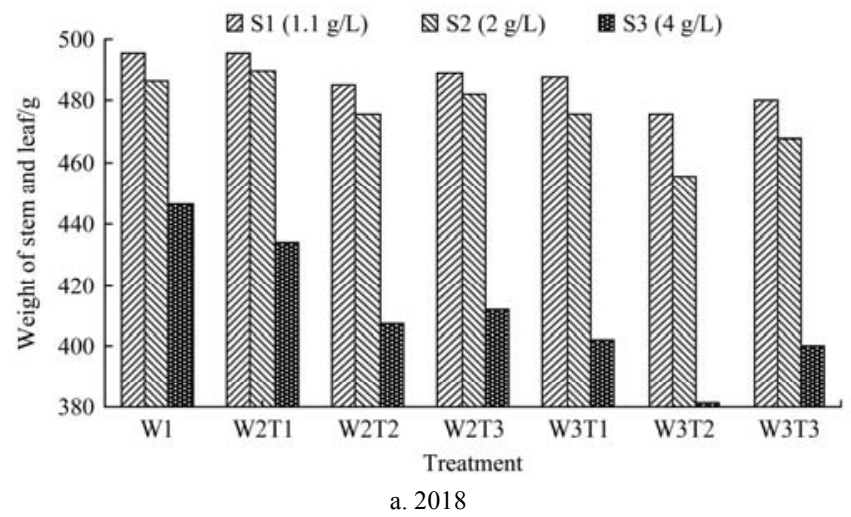

3.3.2 Effects of water and salt regulation on the stems and leaves weight of tomato after harvest time

It can be seen from Figure 4 that the stems and leaves weight of tomato was inversely proportional to the salt concentration of irrigation water, and water deficit treatment during the blossoming and bearing fruits stage has the greatest impact on crop growth. Under fresh water irrigation (S1), deficit irrigation during the seedling stage (T1) can increase the weight of the fresh fruit of the above-ground part of the tomatoes compared with the control group, indicating that the blossoming and bearing fruits stage was sensitive to moisture, and water-saving should not be carried out at blossoming and bearing fruits stage. Because the results of 2018 and 2019 were similar, taking the results of 2018 as an example, with the increase of the salt concentration, compared with W1 treatment, the $\mathrm{W} 2 \mathrm{~T} 2$ under $\mathrm{S} 1, \mathrm{~S} 2$, and $\mathrm{S} 3$ treatments were reduced by $2.13 \%, 4.87 \%$ and $8.74 \%$, respectively. Showing that the larger water and salt stress, the greater the decrease degree in tomato stem and leaf weight. The increased level in stem and leaf weight of tomato under S3 and water deficit treatment during T3 was the largest than S1 and S2 treatments, which was close to seedling treatments. It indicates that under high salt stress no matter what stage occurs water deficit will have a serious impact on the subsequent growth and development of tomatoes. The salinity of $4 \mathrm{~g} / \mathrm{L}$ has exceeded the range that tomatoes can adjust by themselves.

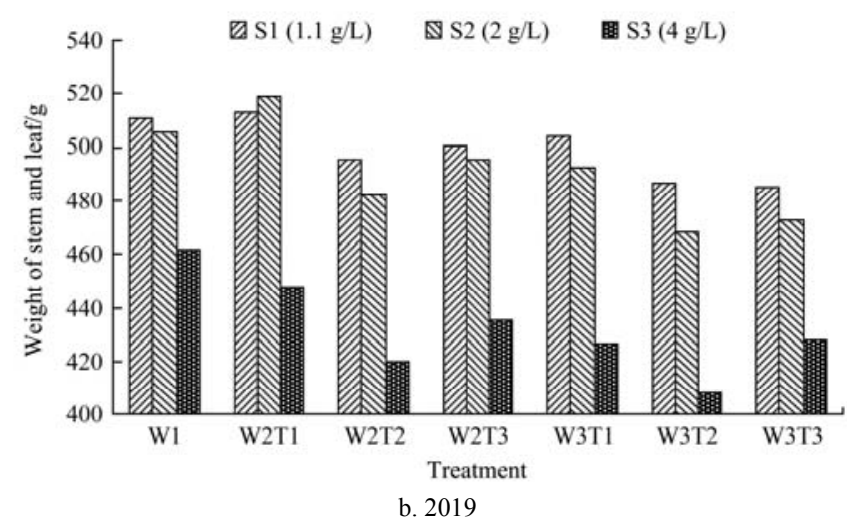

Figure 4 Effects of coordinated regulation of water and salt in different growth stages in 2018 and 2019 on the weight of stems and leaves of tomato after harvest time

3.3.3 Effects of water and salt regulation on the field of tomato and water utilization efficiency

Table 5 shows the yield and water use efficiency of tomatoes under different water and salt control treatments in two years. In both 2018 and 2019, under the low salt stress (S1) treatment, the fresh fruit weight and yield (per plant yield, total yield) of the two cluster fruits were the largest, and the fresh fruit weight and yield of the moderate deficit treatment during the blossoming and bearing fruits stage were the lowest. In different salt concentration treatments, compared with full irrigation treatment, water deficit treatment at all growth stages would reduce tomato yield, but slight water deficit at the seedling stage had no significant effects on tomato yield. Among them, the tomatoes yield under water deficit treatment during blossoming and bearing fruits stage was significantly lower than seedling stage and mature picking stage, and water deficit had the least effect on tomatoes yield at the seedling stage. At the same time, it could be seen that with the increase of salt concentration, the yield per plant showed an obvious downward trend, and there was a significant difference. The main reasons for the significant difference were that in the process of the experiment, the pot experiment was adopted, all of which were exposed to the ground surface, the space restricted the root growth, and the soil environment was inhibited by high temperature, which weakened the stress resistance of tomatoes, and then affected the analysis of variance. By comparing the treatments with different degrees of water deficit in the same stage, it was found that there were significant differences among the treatments with different levels of water deficit in the same stage, and the yield of mild water deficit treatment was significantly higher than moderate water deficit treatment.

Compared with coordinate regulation of water and salt different degrees, the total yield (such as the average yield was $110.36 \mathrm{t} / \mathrm{hm}^{2}$ in 2018) of moderate water deficit treatments (S1W3T1, S1W3T2 and S1W3T3) with low salt stress (S1) was significantly higher than that of mild water deficit treatments (S2W2T1, S2W2T2, and S2W2T3, the average yield of 2018 was $106.44 \mathrm{t} / \mathrm{hm}^{2}$ ) with moderate salt stress (S2), while the differences between moderate salt stress (S2) treatment with moderate water deficit (the average of 2018 was 95.74) and severe salt stress (S3) with mild water deficit treatments (the average of 2018 was 82.71 ) 
are more significant, this shows that the coordinated effect of water deficit can enhance the salt yield reduction effect of irrigation. According to the results of the three-factor analysis of variance, in this experiment, different salt concentrations, water deficit degrees and deficit stages are all significant factors that affecting tomato yield. There was a significant interaction between water $\times$ salt and water $\times$ salt $\times$ deficit stage, however, there was no significant interaction between water $\times$ deficit stage and salt $\times$ deficit stage (' $x$ ' means the interaction effect between various factors). This shows that when considering the coordinated regulation of water and salt, it was mainly affected by irrigation water salinity and the degree of deficit or the interactions of water, salt and deficit stages, and water deficit in different growth stages will not decisively affect the change of the yield per plant. Under different salt concentrations of irrigation water, the relationship of average total yield (2018, 2019) was the low salt concentration treatments greater than moderate salt stress treatments greater than severe salt stress treatments, there were significant differences among different levels; and the average total yield $(2018,2019)$ of no water deficit treatments greater than mild water deficit treatments greater than moderate water deficit treatments, there were significant differences among different treatments; The average yield of each treatment at seedling stage $(2018,2019)$ and mature picking stage $(2018,2019)$ was significantly higher than each deficit treatment at flowering stage $(2018,2019)$.

In 2018, the maximum water use efficiency appeared in S1W3T1 treatments and the minimum appeared in S3W3T2 treatments, they were 37.27 and 23.14 , respectively, there was no significant difference in water use efficiency between S1W3T1 and S1W1 treatments. In 2019, the maximum water use efficiency appeared in S2W2T1 treatment, and the minimum appeared in S3W3T2 treatment, they were 38.98 and 25.26 , respectively, and the differences were significant. In 2018, the water use efficiency with fresh water irrigation treatments was lower than full irrigation treatment except for water deficit at the seedling stage. But in 2019, the water use efficiency of fresh water irrigation treatments with a moderate water deficit was significantly lower than full irrigation. In both two years, the water use efficiencies under water deficit treatment during seedling stage and mature and bearing fruits stage were significantly higher than that at blossoming and bearing fruits stage, and in other brackish water treatments, with the increase of salt concentration, the water use efficiency decreases, which shows that adjusting deficit under the same salt concentration at seedling stage can ensure yield and effectively save water.

Table 5 Effects of different water and salt regulation treatments on the tomato field and water use efficiency in 2018 and 2019

\begin{tabular}{|c|c|c|c|c|c|c|c|c|}
\hline \multirow{2}{*}{ Treatment } & \multicolumn{2}{|c|}{ Weight of two cluster fresh fruits/g } & \multicolumn{2}{|c|}{ Gield of per plant/g $\cdot$ plant $^{-1}$} & \multicolumn{2}{|c|}{ Total field $/ \mathrm{t} \cdot \mathrm{hm}^{-2}$} & \multicolumn{2}{|c|}{ Water use efficiency $/ \mathrm{kg} \cdot \mathrm{m}^{-3}$} \\
\hline & 2018 & 2019 & 2018 & 2019 & 2018 & 2019 & 2018 & 2019 \\
\hline S1W1 & $188.03 \pm 2.97^{\mathrm{a}}$ & $210.62 \pm 1.23^{\mathrm{a}}$ & $4012.72 \pm 20.75^{\mathrm{a}}$ & $4554.80 \pm 39.48^{\mathrm{a}}$ & $132.42 \pm 2.22^{\mathrm{a}}$ & $150.31 \pm 2.23^{\mathrm{a}}$ & 37.04 & 38.16 \\
\hline $\mathrm{S} 1 \mathrm{~W} 2 \mathrm{~T} 1$ & $187.95 \pm 3.66^{\mathrm{a}}$ & $209.32 \pm 3.25^{\mathrm{a}}$ & $4010.80 \pm 12.31^{\mathrm{a}}$ & $4523.60 \pm 41.43^{\mathrm{a}}$ & $132.36 \pm 1.84^{\mathrm{a}}$ & $147.61 \pm 3.15^{\mathrm{b}}$ & 37.28 & 38.92 \\
\hline $\mathrm{S} 1 \mathrm{~W} 2 \mathrm{~T} 2$ & $169.26 \pm 1.62^{\mathrm{cd}}$ & $181.53 \pm 1.27^{\mathrm{d}}$ & $3562.24 \pm 27.13^{\mathrm{abcd}}$ & $3856.64 \pm 49.18^{\mathrm{d}}$ & $116.05 \pm 2.11^{\mathrm{d}}$ & $127.27 \pm 4.2^{\mathrm{e}}$ & 34.52 & 34.50 \\
\hline S1W2T3 & $171.05 \pm 2.37^{\mathrm{c}}$ & $192.40 \pm 2.49^{b}$ & $3605.21 \pm 39.02^{\mathrm{abc}}$ & $4117.68 \pm 30.97^{\mathrm{b}}$ & $118.97 \pm 3.13^{\mathrm{c}}$ & $135.88 \pm 4.11^{\mathrm{c}}$ & 35.97 & 37.46 \\
\hline S1W3T1 & $179.79 \pm 1.43^{\mathrm{b}}$ & $186.47 \pm 1.66^{\mathrm{c}}$ & $3814.96 \pm 13.16^{\mathrm{ab}}$ & $3975.28 \pm 38.59^{\mathrm{c}}$ & $121.89 \pm 1.81^{\mathrm{b}}$ & $131.18 \pm 2.34^{\mathrm{d}}$ & 37.27 & 36.46 \\
\hline S1W3T2 & $136.38 \pm 2.35^{\mathrm{i}}$ & $163.72 \pm 1.71^{\mathrm{gh}}$ & $2773.12 \pm 31.89^{\text {cde }}$ & $3189.28 \pm 31.36^{\mathrm{h}}$ & $100.01 \pm 1.98^{\mathrm{g}}$ & $105.25 \pm 5.05^{\mathrm{i}}$ & 33.60 & 31.91 \\
\hline S1W3T3 & $147.33 \pm 3.04^{\mathrm{g}}$ & $171.49 \pm 1.74^{\mathrm{e}}$ & $3035.92 \pm 23.18^{\mathrm{bcd}}$ & $3615.76 \pm 23.33^{\mathrm{e}}$ & $105.19 \pm 1.59^{\mathrm{f}}$ & $119.32 \pm 5.49^{\mathrm{f}}$ & 34.47 & 33.92 \\
\hline $\mathrm{S} 2 \mathrm{~W} 1$ & $169.27 \pm 3.89^{\text {cd }}$ & $183.41 \pm 3.05^{\mathrm{cd}}$ & $3742.48 \pm 40.4^{\mathrm{abcd}}$ & $4207.84 \pm 29.82^{\mathrm{cd}}$ & $123.56 \pm 2.13^{\mathrm{cd}}$ & $138.76 \pm 1.4 \mathrm{~d}^{\mathrm{e}}$ & 36.48 & 37.72 \\
\hline $\mathrm{S} 2 \mathrm{~W} 2 \mathrm{~T} 1$ & $166.94 \pm 2.22^{\mathrm{d}}$ & $182.62 \pm 3.07^{\mathrm{d}}$ & $3688.56 \pm 13.25^{\mathrm{abcd}}$ & $4176.96 \pm 41.92^{\mathrm{d}}$ & $121.92 \pm 3.25^{\mathrm{d}}$ & $137.94 \pm 3.85^{\mathrm{e}}$ & 37.86 & 38.98 \\
\hline $\mathrm{S} 2 \mathrm{~W} 2 \mathrm{~T} 2$ & $145.78 \pm 4.18^{\mathrm{g}}$ & $160.74 \pm 2.76^{\mathrm{h}}$ & $3179.72 \pm 28.03^{\mathrm{cde}}$ & $3562.84 \pm 29.33^{\mathrm{h}}$ & $104.96 \pm 3.54^{\mathrm{gh}}$ & $117.64 \pm 4.64^{\mathrm{i}}$ & 33.47 & 34.85 \\
\hline $\mathrm{S} 2 \mathrm{~W} 2 \mathrm{~T} 3$ & $152.94 \pm 1.85^{\mathrm{f}}$ & $168.44 \pm 2.89^{\mathrm{ef}}$ & $3350.56 \pm 18.40^{\mathrm{def}}$ & $3767.56 \pm 45.64^{\mathrm{f}}$ & $110.63 \pm 3.02 \mathrm{f}$ & $124.53 \pm 3.93^{\mathrm{g}}$ & 36.60 & 37.29 \\
\hline S2W3T1 & $160.56 \pm 3.68^{\mathrm{e}}$ & $161.38 \pm 1.3^{\mathrm{h}}$ & $3532.44 \pm 40.46^{\text {cde }}$ & $3678.12 \pm 22.45^{\mathrm{g}}$ & $113.66 \pm 2.40^{\mathrm{e}}$ & $121.32 \pm 2.91^{\mathrm{h}}$ & 37.75 & 36.75 \\
\hline S2W3T2 & $129.37 \pm 2.08^{\mathrm{j}}$ & $132.45 \pm 1.19^{j}$ & $2784.88 \pm 28.72^{\mathrm{ghi}}$ & $2978.88 \pm 37.12^{j}$ & $91.96 \pm 1.66^{\mathrm{j}}$ & $98.40 \pm 1.45^{\mathrm{k}}$ & 32.41 & 31.53 \\
\hline S2W3T3 & $135.24 \pm 2.51^{\mathrm{i}}$ & $147.58 \pm 2.72^{\mathrm{i}}$ & $2925.76 \pm 16.07^{\mathrm{fgh}}$ & $3984.92 \pm 40.61^{\mathrm{i}}$ & $96.61 \pm 2.34^{\mathrm{i}}$ & $101.67 \pm 2.24^{j}$ & 34.37 & 35.30 \\
\hline S3W1 & $155.75 \pm 3.36^{\mathrm{f}}$ & $166.52 \pm 1.34^{\mathrm{fg}}$ & $3238.19 \pm 32.43^{\mathrm{de}}$ & $3602.4 \pm 28.96^{\mathrm{f}}$ & $106.85 \pm 1.13^{\mathrm{f}}$ & $118.38 \pm 2.99^{\mathrm{g}}$ & 32.76 & 33.72 \\
\hline $\mathrm{S} 3 \mathrm{~W} 2 \mathrm{~T} 1$ & $142.37 \pm 4.44^{\mathrm{h}}$ & $160.73 \pm 3.32^{\mathrm{h}}$ & $2916.88 \pm 36.97^{\text {efgh }}$ & $3567.44 \pm 48.01^{\mathrm{g}}$ & $96.26 \pm 1.48^{\mathrm{h}}$ & $114.8 \pm 1.64^{\mathrm{h}}$ & 32.31 & 35.61 \\
\hline $\mathrm{S} 3 \mathrm{~W} 2 \mathrm{~T} 2$ & $108.95 \pm 1.74^{\mathrm{m}}$ & $126.2 \pm 3.66^{\mathrm{k}}$ & $2114.83 \pm 41.44^{\mathrm{jk}}$ & $2626.80 \pm 31.29^{\mathrm{k}}$ & $69.79 \pm 2.73^{\mathrm{m}}$ & $86.45 \pm 1.69^{1}$ & 24.85 & 27.86 \\
\hline S3W2T3 & $124.48 \pm 1.13^{\mathrm{k}}$ & $135.61 \pm 1.06^{\mathrm{j}}$ & $2487.52 \pm 16.49^{\mathrm{hij}}$ & $2848.72 \pm 53.44^{\mathrm{ij}}$ & $82.09 \pm 2.34^{\mathrm{k}}$ & $93.91 \pm 4.87^{\mathrm{jk}}$ & 29.63 & 33.28 \\
\hline S3W3T1 & $112.06 \pm 3.82^{1}$ & $126.37 \pm 3.7^{\mathrm{k}}$ & $2189.44 \pm 33.18^{\mathrm{ijk}}$ & $2625.88 \pm 37.48^{\mathrm{k}}$ & $72.25 \pm 1.88^{1}$ & $86.58 \pm 3^{1}$ & 25.71 & 28.33 \\
\hline S3W3T2 & $94.22 \pm 2.01^{\mathrm{n}}$ & $105.22 \pm 2.05^{\mathrm{m}}$ & $1809.28 \pm 37.6^{\mathrm{k}}$ & $2125.28 \pm 51.87^{\mathrm{m}}$ & $60.71 \pm 2.5^{\circ}$ & $70.83 \pm 4.27^{\mathrm{n}}$ & 23.14 & 25.26 \\
\hline S3W3T3 & $101.77 \pm 2.12^{\mathrm{m}}$ & $110.38 \pm 1.93^{1}$ & $1952.98 \pm 39.66^{1}$ & $2246.20 \pm 38.02^{1}$ & $64.42 \pm 2.76^{\mathrm{n}}$ & $74.93 \pm 3.75^{\mathrm{m}}$ & 26.32 & 28.07 \\
\hline Salinity S & $* *$ & $* *$ & $* *$ & $* *$ & $* *$ & $* *$ & $* *$ & $* *$ \\
\hline Deficit degree W & * & * & * & * & * & * & * & * \\
\hline Growth stage $\mathrm{T}$ & $*$ & * & $*$ & * & * & * & * & * \\
\hline $\mathrm{S} \times \mathrm{W}$ & $*$ & * & $*$ & $*$ & $*$ & $*$ & $*$ & * \\
\hline \multicolumn{9}{|l|}{$\mathrm{S} \times \mathrm{T}$} \\
\hline \multicolumn{9}{|l|}{$\mathrm{W} \times \mathrm{T}$} \\
\hline $\mathrm{S} \times \mathrm{W} \times \mathrm{T}$ & $*$ & $*$ & $*$ & $*$ & $*$ & $*$ & $*$ & $*$ \\
\hline
\end{tabular}

Note: After the same column of data, different lowercase letters indicate that there is a significant difference among treatments $(p<0.05) ;{ }^{*}$ means significant difference $(p<0.05) ; * *$ means significant difference $(p<0.01) ; \times$ means the interaction effect between various factors.

\section{Discussion}

Soil electrical conductivity is an indispensable parameter for the study of precision agriculture. It contains rich information that reflects soil quality and physical properties. Soil salt, moisture, temperature, organic matter content, etc., are important factors that affect soil electrical conductivity. Effectively obtaining the value of soil electrical conductivity is of great 
significance for fully exploiting the potential of plants to adapt to drought and salt stress ${ }^{[11]}$. Existing researches mainly focus on improving saline land with new irrigation and drainage technologies ${ }^{[12]}$, the laws of water and salt migration under normal root cultivation conditions ${ }^{[13,14]}$, and the use of modern information technology to manage saline land ${ }^{[15]}$. However, few studies have paid attention to the law of soil salt migration under the condition of water and salt synergy in different growth stages. It can be seen that the average conductivity of $0-30 \mathrm{~cm}$ soil in 2018 was greater than in 2019 from Table 3, this may be related to meteorological factors, in addition, local fresh water and applied fertilizers also have a certain EC value, which accumulates with the increase of irrigation times, so the soil conductivity increases with the increase of the salt concentration of the irrigation water, this was consistent with the conclusion of Guo et al. ${ }^{[16]}$. Long-term brackish water irrigation and the increase of the salinity of the irrigation water will cause the surface accumulation of salt ${ }^{[17]}$. The salt will move down to the root zone of the crop with the irrigation water, inhibiting the absorption of water and nutrients by the crop. The more severe the salt stress was, the more difficult to absorb water for crops, increasing soil moisture content ${ }^{[18]}$. It can be seen from Table 2 that water deficit at the seedling stage and the blossoming and bearing fruits stage can significantly reduce the salt accumulation in the soil. There are different soil salt transport laws at the different water deficit stages. The blossoming and bearing fruits stage with fresh water was a key stage for water consumption. In combination with the tomato yield in two years, water control has a great impact on yield during the blossoming and bearing fruits stage. Therefore, water deficit in the seedling stage can not only ensure the yield also effectively inhibit the production of soil salinization.

Crop water consumption is mainly affected by meteorological factors, crop growth and ground characteristics ${ }^{[19]}$. The research of this paper shows that the water consumption intensity was the highest at the blossoming and bearing fruits stage throughout the whole growth stage, and there was a positive linear relationship between irrigation amount and total evapotranspiration ET, which was consistent with the study by Wang et al. ${ }^{[20]}$ The water consumption during the whole growth stage in this paper was smaller than in previous studies. Firstly, the water consumption of tomatoes will be reduced due to deficit irrigation. In addition, compared with the field experiment environment, the root growth was inhibited in the pot experiment and lacked deep soil water supplement. At the same time, the irrigation water in this experiment has a certain degree of salinity, with the increase of irrigation water, the salt accumulates in the soil, and the vegetative growth of plants before the flowering stage was inhibited, so that the number of leaves, leaf area and stem thickness of the crop are decreased. The reduction of these factors will significantly affect the transpiration of the crop after the flowering stage, thereby affecting the water consumption of the entire growth stage. This was consistent with the research results of Zhang et al. ${ }^{[21]}$ on soybeans, the water-salt interaction can clearly study that salinity can affect the evapotranspiration of tomatoes. The higher the salt was, the smaller the evapotranspiration. With the increase of salinity, the soil infiltration potential decreases, and the ability of crops to use soil moisture also decreases, then it was transformed into water stress, which affects stomatal conductance, leaf growth and photosynthesis, etc ${ }^{[22]}$. The blossoming and bearing fruits stage of tomato was sensitive to salt, so the salt application during this stage should be decreased. Crop water consumption increased under moderate and mild water stress may be that the mechanism of "root water lifting" played a role under certain stress. In addition, under combined water and salt stress, osmotic stress will cause crops to consume more energy during root water absorption, causing redistribution of photosynthetic products, reducing the basic energy required for organ building, resulting in a reduction in crop growth and reducing water consumption, this makes the inhibitory effect of water stress with the additive effect greater than salt stress.

Compared with full irrigation treatment, water deficit during different growth stages will all reduce tomato yield in different salt concentration treatments. However, the mild water deficit during the seedling stage has no significant effect on tomato yield. The yield of water deficit treatments during the blossoming and bearing fruits stage was significantly less than the treatments during the seedling stage and mature picking stage, and there was the least impact on tomatoes when the water deficit occurs in the seedling stage, this result is close to literature which was proposed previously ${ }^{[23,24]}$. When the salinity of irrigation water increases, the yield of tomatoes decreases significantly, and the salt concentration of irrigation water was inversely proportional to tomato yield, which was consistent with previous studies on corn and other crops ${ }^{[25,26]}$. Changes in the proportion of water and salt stress in the water and salt coordinated stress will have different effects on each growth stage. When the salinity stress was dominant, the flowering stage was more sensitive to salinity and yield decreases more, and when the water stress was dominant, the fruiting stage was more sensitive. So, finding a suitable treatment can achieve the purpose of slightly minimizing production under the condition of water deficit and water saving. The blossoming and bearing fruits stage was not suitable for water deficit, it was mainly because the blossoming and bearing fruits stage of tomato was the key stage for yield formation, higher osmotic stress consumed more energy for water absorption, and the assimilation products distributed to the root system, resulted in yield reduction. Since crops consume less water at the seedling stage, so there will not have a great impact on later growth and development under proper water deficit. When evaluating the effect of salt stress on tomato yield, it can be seen that salt stress will significantly reduce the size of the fruit diameter and the weight of tomato stems and leaves. The single fruit weight of tomato decreased significantly with the increase of irrigation salinity in this experiment, which was the same as the studies by Cao et al. ${ }^{[27]}$ Salt has an inhibitory effect on many physiological and biochemical processes, such as changing the hormone secretion processes, inhibiting the height of seed germination plants, changing the development time points, and shortening the growth stage ${ }^{[28]}$; inhibiting the differentiation and growth of plant tissues and organs; reducing leaf area and reducing photosynthetic intensity, resulting in reduced yield ${ }^{[29,30]}$.

\section{Conclusions}

1) Coordinated regulation of water and salt can significantly reduce the electrical conductivity of the tomato root system of 0 $30 \mathrm{~cm}$ soil. The higher the salinity of irrigation was, the better the salt-controlled effect of coordinated regulation of water and salt. Under the influence of coordinated regulation of water and salt, the proportion of water consumption of crop growth and development decreases, and the salinity of irrigation water was a decisive factor in crop water consumption. So, firstly, it is necessary to control the salt intake and then optimize the water distribution.

2) The coordinated regulation of water and salt at different 
growth stages has significant effects on fresh fruit weight, stems and leaves weight when pulling seedlings and yield of tomato, and the salinity of irrigation water was inversely proportional to tomato yield. Moderate water deficit can significantly reduce crop yield, and the degree of crop yield reduction under mild water deficit was weakened, and the blossoming and bearing fruits stage was the most sensitive stage to water deficit.

3) With the increase in salinity of irrigation water, the tomato yield decreased. From the perspective of yield, S1W2T1 treatment (salinity of irrigation water was $1.1 \mathrm{~g} / \mathrm{L}$, mild deficit at the seedling stage, irrigation quantity was $55 \%-65 \%$ of the field water capacity) can ensure yield and reduce irrigation water during the whole growth stage at the same time. From the perspective of water use efficiency, the water use efficiency was highest under S2W2T1 treatment (salinity of irrigation water was $2 \mathrm{~g} / \mathrm{L}$, mild deficit at the seedling stage, irrigation quantity was $55 \%-65 \%$ of field water capacity), compared with the S1W1 treatment in 2018 and 2019 , the yield was reduced by $8.1 \%$ on average, but the water was saved by $10.1 \%$. In 2018 and 2019, the yield per plant with moderate salt stress (salinity of irrigation water was $2 \mathrm{~g} / \mathrm{L}$ ) and severe salt stress (salinity of irrigation water was $4 \mathrm{~g} / \mathrm{L}$ ) decreased by $12.78 \%$ and $21.27 \%$ respectively than fresh water irrigation, and the water deficit in the seedling stage has little effect on the yield, and water can be saved by $10.09 \%$ and $17.42 \%$ respectively when mild water deficit was carried out at the seedling stage.

\section{Acknowledgements}

This work was financially supported by the Applied Basic Research General Project of Yunnan Science and Technology Department (Grant No. 2019FB075).

\section{[References]}

[1] Siddiqui M N, Mostofa M G, Akter M M, Srivastava A K, Sayed M A, Hasan M S, et al. Impact of salt-induced toxicity on growth and yield-potential of local wheat cultivars: Oxidative stress and ion toxicity are among the major determinants of salt-tolerant capacity. Chemosphere, 2017; 187: 385-394.

[2] Li J G, Pu L J, Han M F, Zhu M, Zhang R S, Xiang Y Z. Soil salinization research in China: Advances and prospects. Journal of Geographical Sciences, 2014; 24(5): 943-960.

[3] Qu Z Y, Yang X, Huang Y J. Analysis and Assessment of Water-saving Project of Hetao Irrigation District in Inner Mongolia. Transactions of the CSAM, 2015; 46(4): 70-76. (in Chinese)

[4] Lu J, Shao G C, Zhang K, Wang Z Y, Wang J. Effects of root hydraulic lift on soil salt and tomato yield under water and salt stress. Transactions of the CSAM, 2020; 51(9): 249-257. (in Chinese)

[5] Liu E K, Mei X R, Yan C R, Gong D Z, Zhang Y Q. Effects of water stress on photosynthetic characteristics, dry matter translocation and WUE in two winter wheat genotypes. Agricultural Water Management, 2016; 167: 75-85.

[6] Wang W, Li D Q. The similarities and differences between plant salt stress and water stress. Plant Physiology Journal, 2003; 5: 491-492. (in Chinese)

[7] Orsini F, Pennisi G, Mancarella S, Al Nayef M, Sanoubar R, Nicola S, et al. Hydroponic lettuce yields are improved under salt stress by utilizing white plastic film and exogenous applications of proline. Scientia Horticulturae, 2018; 233: 283-293.

[8] Zhang R, Cheng Z Y, Wang W T, Wu Y X, Niu L L, Zhang X X, et al. Effect of water stress in different growth stages on grape yield and fruit quality under delayed cultivation facility. Transactions of the CSAE, 2014; 30(24): 105-113. (in Chinese)

[9] He X. Influence Mechanisms and the application of water-salt coordinated regulation technique on crop yield and quality. Doctoral dissertation. Beijing: China Agricultural University, 2015; 154p.

[10] Wang X W, Fu Q S, Wang Y Y, Zhang J H, Lu H, Guo Y D. Effects of water stress on growth and photosynthetic system characters of Lycopersicon esculentum L. Journal of China Agricultural University,
2010; 15(1): 7-13. (in Chinese)

[11] Agricultural Chemistry Committee of Soil Society of China Conventional analytical methods of soil agrochemistry. Beijing: Science Press, 1893; 233p. (in Chinese)

[12] Ma L Y, Yao R J, Yang J S. Regulation of nitrogen and fulvic acid on soil organic carbon and aggregates in saline soil. Soils, 2020; 52(1): 33-39. (in Chinese)

[13] Gu Y Y, Yi K H, Liang X Y, Li M, Xu R H, Wang X Y, et al. Effect of salt stress on physicochemical properties of celery soil. Journal of Zhejiang Agricultural Sciences, 2020; 61(9): 1801-1803. (in Chinese)

[14] Demetrio A Z, Pedro A P, Xu X Z, Bruno G C, Manuel E L. Influence of forest stand age on soil water repellency and hydraulic conductivity in the Mediterranean environment. 2021; 753: 142006. doi: 0.1016/ j.scitotenv.2020.142006.

[15] Ehsan Z, Maryam A, Zhao D X, Gunasekhar N, John T. Two-dimensional time-lapse imaging of soil wetting and drying cycle using EM38 data across a flood irrigation cotton field. Agricultural Water Management, 2020; 241: 106383. doi: 10.1016/j.agwat.2020.106383.

[16] Guo A A, Wang M Q, Wang W M, Liu X N, Hu Q J. Study on the effects of brackish water drip irrigation on soil water and salt movement. Anhui Agricultural Science Bulletin, 2019; 25(12): 118-121. (in Chinese)

[17] Zhu C L, Shu M C, Zhang Z Y, Zhai Y M, Min Y, Huang M Y. Effect of alternate irrigation with fresh and brackish water on saline distribution characteristics of soil and growth of summer maize, Transactions of the CSAM, 2017; 48(10): 220-228, 201. (in Chinese)

[18] Yang P L, Wang Y, Ren S M, Wei C C, He X, Xu Z. Soil moisture and saline distribution characteristics and maize stem water uptake under alternate irrigation between saline water and groundwater. Transactions of the CSAM, 2020; 51(6): 273-281. (in Chinese)

[19] Ge J K, Liu Y F, Gong X W, Liu Z J, Li Y B, Xu C D. Response of greenhouse crop ecophysiology, water consumption and yield to ventilation environment regulation. Journal of the Institution of Engineers (India): Series A, 2019; 100(4): 743-752.

[20] Wang X S, Wang S, George T S, Deng Z, Zhang W Z, Fan X C, et al. Effects of schedules of subsurface drip irrigation with air injection on water consumption, yield components and water use efficiency of tomato in a greenhouse in the North China Plain. Scientia Horticulturae, 2020; 269: 109396. doi:10.1016/j.scienta.2020.109396.

[21] Dang Z H, Zheng L L, Wang J, Gao Z, Wu S B, Qi Z, et al. Transcriptomic profiling of the salt-stress response in the wild recretohalophyte Reaumuria trigyna. BMC Genomics, 2013; 14: 29 . doi: 10.1186/1471-2164-14-29.

[22] Chen S F, Zhu Y L, Liu Y L, Li S J. Effects of NaCl Stress on activities of protective enzymes, contents of osmotic adjustment substances and photosynthetic characteristics in grafted tomato seedlings. Acta Horticulturae Sinica, 2005; 4: 609-613. (in Chinese)

[23] Hao S X. Effects of water stress and re-water in different growth stages of tomato on physiological characteristics, fruit quality and yield. Master dissertation. Yangling: Northwest A \& F University, 2019; 68p.

[24] Guo Y B, Feng H, Wu P T. Effects of water stress on physiological characteristic and water production efficiency of tomato. Journal of Irrigation and Drainage, 2008; 3: 52-55. (in Chinese)

[25] Ghannem A, Ben A I, Majdoub R. Effects of regulated deficit irrigation applied at different growth stages of greenhouse grown tomato on substrate moisture, yield, fruit quality, and physiological traits, 2020. doi: 10.1007/s11356-020-10407-w.

[26] Zhu C L, Lyu W, Huang M Y, Zhai Y M, Qiang C. Effects of biochar on coastal reclaimed soil salinity distribution and maize growth with cycle fresh and saline water irrigation. Transactions of the CSAM, 2019; 50(1): 226-234. (in Chinese)

[27] Cao H L, Ding R S, Xue F L. Growth and yield of tomato as impacted by salinity stress. Journal of Irrigation and Drainage, 2019; 38(2): 29-35. (in Chinese)

[28] Wang W Q, Xu L, You S Y, Liu C. Daily salinity fluctuation alleviates salt stress on seedlings of the mangrove Bruguiera gymnorhiza. Hydrological Processes, 2020; 34(11): 2466-2476.

[29] Sharifi P, Bidabadi S S. Strigolactone could enhances gas-exchange through augmented antioxidant defense system in Salvia nemorosa L. plants subjected to saline conditions stress. Industrial Crops \& Products, 2020; 151: 112460. doi: 10.1016/j.indcrop.2020.112460.

[30] Wang W H, Gong Y D, Xing X G. Groundwater evaporation for salt-affected soil under plastic film-covered cultivation condition: A review. Journal of Soil Science and Plant Nutrition, 2020; 20(3): 1229-1237. 